\title{
ESTUDIOS
}

\section{Marcos de acción en la lucha contra el hambre}

\section{Manuel Sánchez Moreno'}

Palabras clave: hambre, desnutrición, seguridad alimentaria, soberanía alimentaria, derecho a la alimentación, justiciabilidad, políticas públicas.

Key words: hunger, malnutrition, food security, food sovereignty, right to food, justiciability, public policies.

Mots clés: faim, malnutrition, sécurité alimentaire, souveraineté alimentaire, droit à l'alimentation, «justiciabilité», politique publiques.

\section{Introducción}

Entre el 16 y el 18 de noviembre de 2009 en Roma se celebró la Cumbre Mundial sobre la Seguridad Alimentaria. En ella el director general del FAO (Organización de las Naciones Unidas para la Alimentación y la Agricultura), Jacques Diouf, declaró que los más de mil millones de hambrientos son "nuestra trágica conquista de la era moderna". Significativas palabras para una Cumbre sobre el principal problema social y político de la humanidad, a la que no asistieron ni los líderes del G8.

En Roma se habló principalmente sobre la necesidad de crear instrumentos de desarrollo económico para impulsar la producción y productividad agrícolas y del

' Historiador y Máster en cooperación al desarrollo y gestión de ONGD (ETEA, con la colaboración de Intermón Oxfam y Entreculturas). En la actualidad disfruta una beca de formación en la Dirección de Cooperación Sectorial y Multilateral de la Agencia Española de Cooperación Internacional y Desarrollo (AECID). 
aumento de la inversión en agricultura como condición previa para el crecimiento económico general. En definitiva, cuestiones técnicas y económicas que puedan promover la cobertura de la necesidad alimenticia. Pero parecen haber olvidado en estos planteamientos generales que esta cobertura obedece también al derecho a la alimentación. ¿¿Dónde está el apoyo a leyes a nivel nacional en materia de alimentación? ¿¿ónde el fortalecimiento de políticas públicas? ¿Dónde los acuerdos jurídicamente vinculantes? En definitiva y sin menospreciar la actuación sobre las consecuencias y las necesidades de las personas jedónde están las medidas para acabar con las causas estructurales del hambre?

Fue una nueva Cumbre sin medidas concretas frente a los más de 1.000 millones de hambrientos, la sexta parte de la población mundial, que lanzaba el Estado de la Inseguridad Alimentaria (SOFI) 2009 de la FAO (Gráfico 1). El SOFI 2010 apunta a un retroceso hasta los 925 millones de personas subnutridas, una cifra que sigue siendo inaceptablemente alta. Esta reducción se debe a la recuperación económica y a la bajada de los precios de los alimentos. Sin embargo el hambre está más extendida que antes de la subida de 2009, lo que dificulta el cumplimiento de los objetivos internacionales para reducir el hambre.

Esta situación evidencia que no estamos sólo ante una cuestión económica, sino política y judicial. El hambre no sólo es de pan, sino de democracia y justicia. La lucha contra el hambre se ha abordado desde distintos marcos que no han mantenido un diálogo efectivo entre sí: derecho a la alimentación, seguridad alimentaria y soberanía alimentaria. El objetivo que nos marcamos es definir y hacer una breve evolución de estos tres marcos para llegar a establecer puntos en común sinérgicos en determinados espacios o mecanismos de protección. El apartado dos será el de las definiciones y evoluciones. En el tercero daremos un ejemplo de temas sinérgicos desde los que trabajar. En el cuarto se concretaran algunos de los mecanismos de protección en los que pueden producirse estas sinergias para que den resultados. Finalmente en el quinto concluiremos con unas recomendaciones generales orientadas a la gobernanza alimentaria.

\section{Definiciones de los marcos}

A continuación realizaremos un breve análisis de los marcos: derecho a la alimentación, seguridad alimentaria y soberanía alimentaria, que nos ayude a comprender cómo se aborda el problema del hambre y la desnutrición desde cada uno de ellos. 


\section{I. Derecho a la alimentación}

Jean Ziegler, anterior relator especial sobre el derecho a la alimentación, en el primero de sus informes periódicos definió el derecho a la alimentación como:

el derecho a tener acceso, de manera regular, permanente y libre, sea directamente, sea mediante compra en dinero, a una alimentación cuantitativa y cualitativamente adecuada y suficiente, que corresponda a las tradiciones culturales de la población a que pertenece el consumidor y que garantice una vida psíquica y física, individual y colectiva, libre de angustias, satisfactoria y digna².

Una definición inseparable de la dignidad humana, que iremos viendo en los documentos de derecho internacional referidos principalmente a los derechos económicos, sociales y culturales.

El artículo 25 de la Declaración Universal de los Derechos Humanos (1948) dice:

Toda persona tiene derecho a un nivel de vida adecuado que le asegure, así como a su familia, la salud y el bienestar, y en especial la alimentación, el vestido, la vivienda, la asistencia médica y los servicios sociales necesarios.

Aquí se perfila el derecho a la alimentación como individual, social y fundamental ya que apela al mínimo vital, a la vida y a la vida con dignidad.

Es esta una declaración de carácter ético y no vinculante para lo cual se firmaron dos pactos. El derecho a la alimentación pertenece principalmente al Pacto internacional de derechos económicos, sociales y culturales (PIDESC) (1966). Buceando en el PIDESC podemos encontrar una mayor profundización del derecho a la alimentación en su artículo 11, donde:

Los Estados Partes en el presente Pacto reconocen el derecho de toda persona a un nivel de vida adecuado para sí y su familia, incluso alimentación [...]. Los Estados Partes tomarán medidas apropiadas para asegurar la efectividad de este derecho, reconociendo a este efecto la importancia esencial de la cooperación internacional fundada en el libre consentimiento.

Es responsabilidad de los Estados que han ratificado este Pacto, jurídicamente vinculante, garantizar el derecho a la alimentación a su ciudadanía mediante sus

2 El derecho a la alimentación. Informe preparado por el Sr. Jean Ziegler, Relator Especial sobre el derecho a la alimentación, de conformidad con la resolución 2000/10 de la Comisión de Derechos Humanos (2001) párrafo 14. 
recursos o haciendo uso de la cooperación internacional, si no pudieran hacerlo por sí solos.

En el segundo párrafo de este mismo artículo se empiezan a definir algunas dimensiones del derecho a la alimentación. Se esboza en qué consiste tal derecho: «mejorar los métodos de producción, conservación y distribución de alimentos» y «asegurar una distribución equitativa de los alimentos mundiales en relación con las necesidades». También introduce dos temas fundamentales que se han tocado insuficientemente en los planos internacional y nacional: «el perfeccionamiento - la reforma de los regímenes agrarios de modo que se logren la explotación y la utilización más eficaces de las riquezas naturales» y «los problemas que se plantean tanto a los países que importan productos alimenticios como a los que los exportan». Dado el carácter vinculante del Pacto, son dos temas que se deben abordar obligatoriamente por los países ratificantes.

En todo el Pacto hay una tensión no resuelta entre asegurar inmediatamente el derecho a la alimentación y asegurarlo de forma progresiva. Si la consideración de derecho fundamental nos obliga a asegurarlo mediante la primera forma, la cantidad de medidas económicas, políticas y sociales que ello conlleva resuelve asegurarlo en la segunda. Indistintamente, el derecho a la alimentación es vital y se puede abordar de ambas maneras, como veremos más adelante.

Para acelerar este proceso la Cumbre Mundial de la Alimentación (CMA) de 1996 solicitó a la ONU una Observación general derivada del artículo 11 del PIDESC: la Observación general $n .{ }^{\circ} 12$ sobre el derecho a la alimentación adecuada aprobada en mayo de 1999. Para lograr un enfoque integrado y coordinado en la promoción del derecho a la alimentación la primera medida establecida por esta Observación fue nombrar por un periodo de tres años a un Relator especial sobre el derecho a la alimentación ${ }^{3}$. Y en el mismo orden de importancia estableció entre sus párrafos 7 y 13 , los elementos constitutivos del derecho a la alimentación. Estos explican en qué consiste el derecho a la alimentación en los siguientes términos:

I. Adecuación: los alimentos disponibles para satisfacer el derecho a la alimentación deben ser adecuados a las condiciones sociales, económicas, culturales, climáticas, ecológicas y de otro tipo imperantes en un espacio y tiempo determinado.

II. Sostenibilidad: posibilidad de acceso a los alimentos por parte de las generaciones presentes y futuras.

${ }^{3}$ Hasta el 2008 fue Jean Ziegler y desde entonces es Olivier de Schutter. 
III. Aceptabilidad: la disponibilidad de alimentos en cantidad y calidad suficientes para satisfacer las necesidades alimentarias de los individuos, sin sustancias nocivas, y aceptables para una cultura determinada.

IV. Alimentación suficiente: la que aporta la combinación de productos nutritivos suficientes para satisfacer las necesidades fisiológicas humanas.

V. Inocuidad: los alimentos deben carecer de sustancias nocivas, para lo cual debe establecerse una serie de medidas de protección en lo público y en lo probado con el fin de evitar la contaminación de los alimentos por la adulteración, mala higiene ambiental o manipulación incorrecta en las etapas de la cadena alimentaria.

VI. Respeto a las culturas: los alimentos deben ser aceptables para una cultura o unos consumidores determinados, por lo que hay que tener en cuenta, valores no relacionados con la nutrición que se asocian a los alimentos, así como las preocupaciones fundamentadas de los consumidores acerca de la naturaleza de los alimentos disponible.

VII. Disponibilidad: las personas tienen la posibilidad de alimentarse directamente de la tierra, de otros recursos naturales o de unos sistemas de distribución, procesamiento y comercialización eficaces. También incluye el respeto del Estado, cuando actúe a nivel internacional, de respetar el derecho a la alimentación en otros países, proteger este derecho, facilitar el acceso a los alimentos y prestar la ayuda necesaria cuando se le solicite.

VIII. Accesibilidad: tanto económica (mediante actividad económica, subsidios adecuados o ayuda) como física (especialmente para los grupos vulnerables) a través de programas especiales. Los grupos de vulnerabilidad vienen marcados por conflictos políticos o desastres naturales.

Estos elementos constitutivos conviven con las categorías estandarizadas de los derechos humanos: disponibilidad, accesibilidad, aceptabilidad, calidad, participación y sostenibilidad.

El párrafo 15 de la Observación establece como último responsable y garante de estas dimensiones al Estado, dándole cuatro obligaciones:

I. Respetar el acceso a la alimentación.

II. Proteger que empresas y particulares no priven a las personas el acceso a una alimentación adecuada. 
III. Facilitar el acceso de la población a los recursos que aseguren su seguridad alimentaria.

IV. Hacer efectivo el derecho a la alimentación entre las personas vulnerables incluidas las víctimas de un desastre natural.

Los párrafos 17 a 20 tratan de la violación del derecho, estableciendo unos niveles mínimos para el Estado. La violación puede ser por dos motivos: falta de capacidad o falta de voluntad del Estado. Este es de una extraordinaria importancia ya que alude a la "omisión activa" o no intervención del Estado para evitar hambrunas y/o crisis alimentarias. Otro tipo de violación está basado en el principio de no discriminación en el acceso a los alimentos o a los medios y derechos para obtenerlos por motivos de género, etnia, religión, etc. Tales violaciones pueden producirse por actos realizados directamente por los Estados o por entidades insuficientemente regladas por los Estados, véase las multinacionales, advirtiendo que aunque los últimos responsables son los Estados firmantes del Pacto, también tienen responsabilidades las ONGD, sociedad civil y sector empresarial privado. El Estado debería crear un medio que facilitara el ejercicio de esas responsabilidades, y ahí entramos en el terreno de la aplicación mediante medidas e instrumentos administrativos y legislativos a nivel nacional, es decir en la creación de leyes nacionales sobre seguridad alimentaria y de políticas públicas a las que luego iremos.

Estas estrategias nacionales deben cumplir los principios de responsabilidad, transparencia, participación popular, descentralización, capacidad legislativa e independencia de la magistratura, es decir buen gobierno (párrafo 23). En la creación de leyes se observa la asistencia de organismos como la FAO (párrafo 30), manteniendo una vigilancia nacional e internacional con respecto al Pacto y dando recursos judiciales en el plano nacional e internacional a las víctimas de violación del derecho a la alimentación (párrafo 32). En estos últimos párrafos se insta a los estados a que aseguren los elementos constitutivos del derecho a la alimentación mediante la creación de leyes nacionales, políticas públicas y mecanismos de reparación jurídicos o administrativos si se vulnera el derecho.

Analizando detenidamente el PIDESC y la Observación general $\mathrm{n} .^{\circ} 12$, se ha visto el amplio perímetro del derecho a la alimentación en relación con la agricultura, el comercio, la salud, etc. todo un nudo gordiano que hace más compleja su implementación al requerir un enfoque multisectorial ${ }^{4}$.

${ }^{4}$ El derecho a la alimentación. Op. cit. (2001) párrafos 68-80. 
El derecho a la alimentación también está presente en otras convenciones, aunque sin la extensión del artículo 11 del PIDESC ni de su Observación general. Así, el artículo 12 de la Convención sobre la Eliminación de todas las formas de Discriminación contra la Mujer (1979) sólo alude a una nutrición adecuada durante el embarazo y la lactancia. En los artículos 24 y 27 de la Convención sobre los Derechos del Niño de 1989, se alude a las cuestiones alimenticias que deben proteger los Estados, como el suministro de alimentos nutritivos adecuados y la información tanto a padres como a niños sobre salud y nutrición. También contempla el derecho de los niños a recibir una pensión alimenticia. Para finalizar, es interesante mencionar el artículo 24 del Convenio sobre pueblos indígenas y tribales 169 (1989) de la Organización Internacional del Trabajo (OIT), donde no se menciona expresamente el derecho a la alimentación, pero sí el principio de no discriminación por motivos étnicos en los regímenes de seguridad social, así como el derecho a participar en las políticas que les afecten y en decidir su propio desarrollo, estando implícita la alimentación.

Este convenio es especialmente interesante porque al enfoque multisectorial se une el enfoque de diversidad desde la participación activa en la toma de decisiones y el principio de no discriminación. Esto supone terminar con todas las barreras hacia un trato diferente (de exclusión, preferencia o distinción) basado en características personales como género, sexo, etnia, religión, discapacidad, clase socioeconómi$\mathrm{ca}$, edad, orientación sexual, etc., que tenga como efecto menoscabar o anular la equidad de trato y oportunidad de las personas.

\subsection{Seguridad alimentaria}

Si queremos hacer historia, el concepto de seguridad alimentaria se remonta a principios del siglo XIX con el economista inglés Robert Malthus. Hambrunas y hambre en sentido lato se explicaban por una disminución de la disponibilidad de alimentos junto con un excesivo crecimiento demográfico. La CMA de 1974 siguió de cerca este concepto para definir la seguridad alimentaria nacional: disponibilidad de unos suministros alimentarios per cápita suficientes en el ámbito de un país en todo momento, mediante el aumento de la producción, las reservas - las importaciones ${ }^{5}$. La seguridad alimentaria nacional centraba su análisis en valores agregados promedio, es decir el total de los suministros alimentarios dividido entre el total de la población, obviando que de esta manera no se tenían en cuenta las brechas de desigualdad entre distintos estratos poblacionales. El

${ }^{5}$ Pérez de Armiño, K. (1998) p. 7. 
objetivo político era incrementar el abastecimiento pero sin políticas redistributivas de los recursos.

Las críticas no tardaron. Por un lado se identificó el problema del hambre no sólo como una falta de alimentos, de su disponibilidad sino de acceso a los mismos obviando factores como la discriminación. Por otro lado, se mostró la necesidad de analizar pormenorizadamente a la población, desechando los datos per cápita que no aluden a la desigualdad. De este modo Amartya Sen planteó en 1981 la "teoría de las titularidades" 6 , basada en el acceso a los alimentos por parte de la población vulnerable.

Las titularidades (acceso) al alimento consisten en las capacidades de una familia o una persona para acceder a los alimentos de manera legal, produciéndolo, comprándolo o percibiéndolo como donación del Estado o de una comunidad. Es un concepto determinado por las relaciones de intercambio de mercado y por el nivel de protección social.

Así, a principios de los 80 surge el concepto de seguridad alimentaria familiar, como ampliación de la seguridad alimentaria nacional, que se define como: "el acceso de todas las personas, en todo tiempo, a cantidades de alimentos suficientes para una vida activa y saludable» ${ }^{7}$. Definición algo insípida que se deja en el tintero la multisectorialidad del fenómeno del hambre con la salud, las estrategias familiares en épocas de crisis, la hambruna como arma de guerra, las cuestiones de género, etc. A pesar de ello, la seguridad alimentaria familiar centra las causas y soluciones de la pobreza en medidas redistributivas, pasando de un enfoque macro a otro micro ${ }^{8}$.

Deberemos esperar a la Declaración de Roma y su Plan de Acción de 1996 para tener la definición internacionalmente aceptada. Su párrafo 1 dice: «seguridad alimentaria, a nivel de individuo, hogar, nación, global, se consigue cuando todas las personas en todo momento tienen acceso físico y económico a suficiente alimento, seguro y nutritivo, para satisfacer sus necesidades alimenticias y sus preferencias, con el objeto de llevar una vida activa y sana». La seguridad alimentaria se ve principalmente como un problema de acceso y

\footnotetext{
${ }^{6}$ SEN, A. (1981).

7 Banco MUNDIAL (1986) p. 1.

8 Pérez de Armiño, K. (1998) p. 8.
} 
disponibilidad alimentarios, sin tener demasiado en cuenta los conceptos de utilización, estabilidad, sostenibilidad, alimentación nutritiva o preferencias culturales ${ }^{9}$ que completan no sólo este concepto de seguridad alimentaria sino el de derecho a la alimentación, como hemos visto.

En la línea de la Declaración de Roma, el Instituto de Nutrición para Centroamérica y Panamá define la seguridad alimentaria nutricional como: "un estado en el cual todas las personas gozan, en forma oportuna y permanente, de acceso físico, económico y social a los alimentos que necesitan, en cantidad y calidad, para su adecuado consumo y utilización biológica, garantizándoles un estado de bienestar general que coadyuve al logro de su desarrollo». Concepto muy usado en Centroamérica donde no sólo nos encontramos el problema del hambre como acceso a los alimentos sino de la desnutrición o malnutrición (Gráfico 2). Pero este concepto resulta algo pobre o excesivamente técnico al no contemplar la multisectorial y los aspectos políticos del hambre. Consecuentemente la inseguridad alimentaria se define en el SOFI de 2000 como una «situación que se da cuando las personas carecen de acceso seguro a suficientes alimentos inocuos y nutritivos para un crecimiento y desarrollo normales y una vida activa y sana». Algo que afecta especialmente a las personas vulnerables.

Los componentes básicos de la seguridad alimentaria nutricional son ${ }^{10}$ :

I. Disponibilidad de alimentos a nivel local o nacional: tiene en cuenta la producción, las importaciones, el almacenamiento y la ayuda alimentaria. Para sus estimaciones se han de tener en cuenta las perdida postcosecha y las exportaciones.

II. Estabilidad: se refiere a solventar las condiciones de inseguridad alimentaria transitoria de carácter cíclico o estacional, a menudo asociadas a las campañas agrícolas, tanto por la falta de producción de alimentos en momentos determinados del año, como por el acceso a recursos de las poblaciones asalariadas dependientes de ciertos cultivos. En este componente juegan un papel importante la existencia de almacenes o silos en buenas condiciones, así como la posibilidad de contar con alimentos e insumos de contingencia para las épocas de déficit alimentario.

\footnotetext{
9 BINDRABAN, P. S.; BrousWer, I. D. y MOLL, H. A. (2006) pp. 67-68.

${ }^{10}$ De Loma-Ossorio, E. y Lahoz, C. (2004).
} 
III. Acceso y control sobre los medios de producción (tierra, agua, insumos, tecnología, conocimiento...) y a los alimentos disponibles en el mercado: la falta de acceso y control es frecuentemente la causa de la inseguridad alimentaria, y puede tener un origen físico (cantidad insuficiente de alimentos debido a varios factores, como son el aislamiento de la población, la falta de infraestructuras...) o económico (ausencia de recursos financieros para comprarlos debido a los elevados precios o a los bajos ingresos).

IV. Consumo y utilización biológica de los alimentos: el consumo se refiere a que las existencias alimentarias en los hogares respondan a las necesidades nutricionales, a la diversidad, a la cultura y las preferencias alimentarias. También hay que tener en cuenta aspectos como la inocuidad de los alimentos, la dignidad de la persona, las condiciones higiénicas de los hogares y la distribución con equidad dentro del hogar. Así como el uso individual de los alimentos (ingestión, absorción y utilización).

Podemos afirmar que la seguridad alimentaria es un concepto técnico como se deriva de sus componentes, muy diferentes de los elementos constitutivos del derecho a la alimentación que asume la disponibilidad, estabilidad, acceso y consumo y utilización biológica e incorpora otras cuestiones tan cruciales como la sostenibilidad y la participación. Al ser un concepto técnico no tiene vinculación política o jurídica, es por lo tanto una herramienta.

Sin prejuicio de lo anterior, las sucesivas Cumbres Mundiales de la Alimentación, en el seno de Naciones Unidas han vinculado las medidas técnicas de la seguridad alimentaria con el marco normativo ofrecido por el derecho a la alimentación. Estas cumbres han sido desarrolladas por la FAO para lograr una mejor gestión de la gobernanza mundial de la seguridad alimentaria ${ }^{11}$. Sin embargo, han estado más cargadas de buenas intenciones que de fuerza vinculante por los intereses divergentes y descoordinación de los países que componen la FAO, la ausencia de una visión holística de los derechos humanos y multisectorial de la alimentación y una falta de exigibilidad y rendición de cuentas mutua respecto a los compromisos adquiridos.

La primera CMA data de 1974, donde se ofreció el citado concepto de seguridad alimentaria y se mencionaron en la Declaración universal sobre la erradicación del hambre y la malnutrición aspectos interesantes referidos a las políticas agrarias, a comercio y a la exportación. Se creó también el Comité de Seguridad Alimentaria

${ }^{11}$ Instituto de Estudios del Hambre (2010). 
(CSA), con el fin de servir de órgano intergubernamental dentro de la ONU para el examen y seguimiento de las políticas y programas relativos a la seguridad alimentaria mundial. Un órgano que actualmente está en proceso de reforma. Durante la CMA de 1996 se aprobó la Declaración de Roma sobre la Seguridad Alimentaria Mundial, en la que los participantes se comprometieron a aplicar, vigilar y dar seguimiento al Plan de Acción cuya finalidad era la de reducir a la mitad el número de personas desnutridas antes del 2015.

El punto siete del Plan de Acción se desarrolla en los siguientes objetivos:

I. Adoptar medidas dentro del marco nacional de cada país con miras a mejorar la seguridad alimentaria y permitir el cumplimiento de los compromisos contraídos en el Plan de Acción de la CMA.

II. Mejorar la cooperación subregional, regional e internacional y movilizar los recursos disponibles, haciendo un uso óptimo de ellos para apoyar los esfuerzos nacionales con objeto de conseguir lo antes posible una seguridad alimentaria mundial sostenible.

III. Vigilar activamente el Plan de Acción de la CMA.

IV. Esclarecer el contenido del derecho a una alimentación suficiente y del derecho fundamental de toda persona a no padecer hambre, como se declara en el PIDESC y otros instrumentos internacionales y regionales pertinentes, y prestar especial atención a la aplicación y la realización plena y progresiva de este derecho como medio de conseguir la seguridad alimentaria para todos.

V. Compartir las responsabilidades de la consecución de la seguridad alimentaria para todos, de manera que la aplicación del Plan de Acción de la CMA se lleve a cabo al nivel más bajo posible al que pueda conseguirse su mejor objetivo.

Quizá sea este último punto el que debamos relacionar con la Cumbre del Milenio, celebrada en Nueva York a finales de 2000. En esta convocatoria de la ONU 189 países se comprometieron a hacer el máximo esfuerzo para avanzar en la erradicación de la pobreza y el hambre y en la promoción de la educación, la salud, la equidad de género y la sostenibilidad medioambiental para el 2015. Estos propósitos quedaron plasmados en la consecuente Declaración del Milenio, que dio lugar a los Objetivos para el Desarrollo del Milenio (ODM), ocho grandes desafíos en torno a los cuales se debían concentrar los esfuerzos de la comunidad internacional. Todo ello suponía una síntesis de las cumbres de los 90. Estos 8 
ODM se tradujeron en 18 metas y unos 48 indicadores para su seguimiento, que se han ido modificando.

El ODM 1 pretende erradicar la pobreza extrema y el hambre, siendo su meta 3: reducir a la mitad, entre 1990 y 2015 , el porcentaje de personas que padecen hambre, con tan sólo dos indicadores para medir los progresos: el porcentaje de menores de 5 años con peso inferior al normal y el porcentaje de la población por debajo del nivel mínimo de consumo de energía alimentaria. Indicadores incompletos que no se están consiguiendo en más de la mitad de los países con información disponible. Hay una brecha respecto al derecho a la alimentación ya que no tiene en cuenta sus distintas categorías, la multisectorialidad y la diversidad.

En junio de 2002 se celebró en Roma la Cumbre Mundial de la Alimentación: cinco años después, que reafirma su compromiso de reducir a la mitad el número de personas desnutridas antes de 2015 (Cuadro 1). Pero aquí se da un paso más al anunciar en su Declaración Final que el Consejo de la FAO elaborará en un periodo de dos años «un conjunto de directrices voluntarias para apoyar los esfuerzos de los Estados miembros encaminados a alcanzar la realización progresiva del derecho a una alimentación adecuada en el contexto de la seguridad alimentaria nacional; pedimos a la FAO que, en colaboración con los órganos pertinentes creados en virtud de tratados, organismos y programas del sistema de Naciones Unidas, preste sus trabajos al grupo de trabajo intergubernamental, el cual deberá informar sobre sus trabajos al Comité de Seguridad Alimentaria Mundial».

Partiendo del penúltimo punto se realizaron las Directrices voluntarias en apoyo de la realización progresiva del derecho a una alimentación adecuada en el contexto de la seguridad alimentaria nacional, que fueron aprobadas por el Consejo de la FAO el 24 de noviembre de 2004 y aunque constituyen un importante logro y una acertada hoja de ruta sobre la aplicación del derecho a la alimentación ${ }^{12}$ no son jurídicamente vinculantes, limitándose a ser una herramienta práctica para el diseño de estrategias nacionales de lucha contra el hambre. A pesar de ello son muy valiosas al ayudar a implementar de forma integral el derecho a la alimentación a nivel nacional mediante una serie de medidas para aplicar en las políticas públicas.

El documento se divide en tres bloques:

\footnotetext{
12 Los Derechos Económicos, Sociales y Culturales. El derecho a la alimentación. Informe del relator Especial sobre el derecho a la alimentación, Jean Ziegler (2005) párrafo 7.
} 
1. Prefacio e introducción. En el párrafo 2 se establece que el documento emana de los objetivos del Plan de Acción de la CMA. En el párrafo 7 se afirma: «en las Directrices voluntarias se tienen en cuenta una amplia gama de importantes consideraciones y principios, como la igualdad y la ausencia de discriminación, la participación y la inclusión, la obligación de rendir cuentas y el estado de derecho, y el principio de que todos los derechos humanos son universales, indivisibles e interdependientes y están relacionados entre sí. Los alimentos no deberían utilizarse como instrumento de presión política y económica.»

II. Entorno propicio, asistencia y rendición de cuentas, que contiene las 19 directrices con una amplitud temática como buen gobierno, marco jurídico, comercio, ayuda alimentaria, catástrofes naturales, acceso a recursos como el agua $\circ$ la tierra, algunos de ellos tan novedosos como la introducción de educación y sensibilización (directriz 11), centrada en la formación técnica, agraria y sobre el derecho a la alimentación a campesinos, funcionarios, en escuelas y en general a la sociedad civil que debe tener «los medios necesarios para que participe en la aplicación de las directrices, por ejemplo, mediante la creación de capacidad». Este enfoque informativo y participativo aparece varias veces en el documento, algo que es de agradecer ya que los ciudadanos deben «fortalecer su capacidad para participar en las decisiones sobre las políticas relacionadas con la alimentación que les pueden afectar y para impugnar las decisiones que amenacen sus derechos».

III. Medidas, acciones y compromisos internacionales. Aquí se define el papel de la comunidad internacional en base a los compromisos adquiridos, hablando de la cooperación técnica, el comercio internacional, deuda externa, ayuda oficial al desarrollo, compromisos raramente llevados a la práctica. El documento termina con una rendición de cuentas voluntaria de los Estados ante el CSA de los progresos realizados en la aplicación y consecución de las Directrices voluntarias.

Es interesante destacar la Declaración de Córdoba sobre el derecho a la alimentación y la gobernanza del sistema mundial de agricultura y alimentación promovida por la CEHAP (Cátedra de estudios sobre hambre y pobreza de la Universidad de Córdoba), redactada en 2008 por un grupo de expertos internacionales entre los que destacan Barbara Ekwall, coordinadora de la Unidad del Derecho a la Alimentación de la FAO y Olivier de Schutter, actual relator especial del derecho a la alimentación de Naciones Unidas. Aquí se consideran aspectos como la coordinación institucional, la agricultura a pequeña escala, el enfoque de derechos en las políticas, la participación de la sociedad civil y la rendición de cuentas mutua. 
Esta Declaración surge en el contexto de la crisis de los precios de los alimentos. lgual motivación tuvo la creación en 2008 del Equipo de Tareas de Alto Nivel de Naciones Unidas para la Crisis Alimentaria (HLTF), que trata de coordinar a las agencias de la ONU con competencias en seguridad alimentaria, gobiernos, instituciones de Bretton Woods y sociedad civil mediante foros de consulta. Intenta conciliar y coordinar una acción unificada para combatir la inseguridad alimentaria. El HLTF presentó en 2008 un Marco Amplio para la Acción (CFA). Sus dos objetivos tratan paliar inmediatamente la disponibilidad de alimentos y fortalecer a largo plazo la seguridad alimentaria y nutricional, encaminándose al ODM 1. Tras la conformación del HTLF se han venido celebrando un buen número de reuniones internacionales en torno a la crisis de precios de los alimentos.

Es destacable la reunión especial con motivo de la subida al precio de los alimentos que el relator especial para el derecho a la alimentación, Olivier de Schutter, promueve en el Consejo de Derechos Humanos de la ONU, en mayo de 2008. El relator propone una acción coordinada de la comunidad internacional, guiada bajo leyes internacionales que obliguen a todos los Estados a proteger el derecho a la alimentación ${ }^{13}$. También un grupo de organizaciones de la sociedad civil hacen un pronunciamiento en el Consejo de Derechos Humanos donde manifiestan que las políticas internacionales están desorientadas al ser aplicadas por las instituciones de Bretton Woods y la Organización Mundial del Comercio $(\mathrm{OMC})^{14}$. Este mismo año tuvo lugar la Conferencia de Alto Nivel sobre Seguridad Alimentaria Mundial, sin acuerdos ni fuerza vinculante. No obstante en la reunión del G8 en Hokkaido aprueban una declaración sobre seguridad alimentaria y la creación de una Alianza Global para la Agricultura y la Alimentación.

En 2009 tuvo lugar en Madrid la Reunión de Alto Nivel sobre Seguridad Alimentaria para Todos (RANSA), donde se establece que el derecho a la alimentación es el tercer objetivo fundamental para el CFA y que son necesarias más consultas con la sociedad civil. Fue un error considerar al derecho a la alimentación como otro elemento, y no elemento integrado bajo un enfoque de derechos en los dos objetivos. Tampoco es acertado consultar a la sociedad civil, sino incluirla en las decisiones. Ese mismo año, la reunión del G8 planteó Los acuerdos de L'Aquila que proponen una serie de medidas como eliminar las restricciones a las exportaciones

\footnotetext{
${ }^{13}$ Analysis of the word food crisis by the U.N special rapporteur on the right to food, Olivier de Schutter (2008) y Statement of the Special Rapporteur on the Right to Food Mr. Olivier De Schutter (2008).

${ }^{14}$ El mundo ya no necesita más de esta medicina (2008).
} 
con motivos, implementar la Ronda de Doha o incrementar las inversiones públicas de los países africanos en agricultura.

Finalmente, destacar la Tercera Cumbre Mundial sobre Seguridad Alimentaria, a la que se ha hecho alusión al principio de este artículo. En la actualidad, la gobernanza de la seguridad alimentaria está en pleno proceso de transformación desde Naciones Unidas. Se tendrán que reformular las competencias y dotar de contenidos y acciones todos los instrumentos creados.

\subsection{Soberanía alimentaria}

Es un concepto promovido por Vía Campesina, un movimiento internacional de campesinos, pequeños productores, mujeres rurales, indígenas, etc. que desde la década de los 90 defienden sus valores en foros paralelos a las Cumbres Mundiales de la Alimentación. Es un movimiento autónomo, plural, multicultural, independiente formado por organizaciones de 56 países de todo el mundo. Desde 1996 diversas Conferencias Internacionales paralelas a las que hemos visto de la FAO fueron definiendo el concepto de soberanía alimentaria. La definición más completa es la del Foro Mundial de la Alimentación en Nyéléni (Malí) en febrero 2007:

La soberanía alimentaria es el derecho de los pueblos a alimentos nutritivos y culturalmente adecuados, accesibles, producidos de forma sostenible y ecológica, y su derecho a decidir su propio sistema alimentario y productivo. Esto pone a aquellos que producen, distribuyen y consumen alimentos en el corazón de los sistemas y políticas alimentarias, por encima de las exigencias de los mercados y de las empresas. Defiende los intereses de, e incluye a, las futuras generaciones. Nos ofrece una estrategia para resistir y desmantelar el comercio libre y corporativo y el régimen alimentario actual, y para encauzar los sistemas alimentarios, agrícolas, pastoriles y de pesca para que pasen a estar gestionados por los productores y productoras locales. La soberanía alimentaria da prioridad a las economías locales y a los mercados locales y nacionales, y otorga el poder a los campesinos y a la agricultura familiar, la pesca artesanal y el pastoreo tradicional, y coloca la producción alimentaria, la distribución y el consumo sobre la base de la sostenibilidad medioambiental, social y económica. La soberanía alimentaria promueve el comercio transparente, que garantiza ingresos dignos para todos los pueblos, y los derechos de los consumidores para controlar su propia alimentación y nutrición. Garantiza que los derechos de acceso y a la gestión de nuestra tierra, de nuestros territorios, nuestras aguas, nuestras semillas, nuestro ganado y la biodiversidad, estén en manos de aquellos que producimos los alimentos. La soberanía alimentaría supone nuevas relaciones sociales libres de opresión y desigualdades entre los hombres y mujeres, pueblos, grupos raciales, clases sociales y generaciones.

Es una definición que amplía la más técnica de la seguridad alimentaria e incorpora plenamente el derecho a la alimentación desde los pequeños agricultores, desde lo 
nacional, desde lo local y sobretodo desde lo participativo. Subraya estos aspectos endógenos sobre los más exógenos de la seguridad alimentaria. Otro carácter a destacar es el enfrentamiento a los procesos de globalización excluyentes en lo que respecta al comercio o las multinacionales, fenómeno que tiende a excluir a las personas más vulnerables.

La soberanía alimentaria desconfía de muchos gobiernos y organismos internacionales centrándose en el quehacer sinérgico de pequeños agricultores y movimientos sociales y su capacidad de hacer presión política para cambiar las distintas estructuras multidimensionales que rodean al hambre. En la introducción a las Directrices voluntarias se alude a "la necesidad de poner a las personas en condiciones de realizar el derecho a tomar parte en la gestión de los asuntos públicos, el derecho a la libertad de expresión y el derecho a buscar, recibir y transmitir información, incluso en relación con la adopción de decisiones relativas a las políticas para la realización del derecho a una alimentación adecuada [...] los ciudadanos consideran que sus gobiernos tienen que rendir cuentas y participan en los procesos de desarrollo humano, en lugar de limitarse a ser receptores pasivos». Aunque la soberanía la ejercen los gobiernos, el verdadero titular de la misma es la ciudadanía.

La soberanía alimentaria es un intento de poder decidir frente a modelos de seguridad alimentaria impuestos, que no se ajustan a las prácticas culturales y que pueden perjudicar al medioambiente. En definitiva se trata de dar voz a todos estos movimientos sociales que son los principales protagonistas del problema del hambre, en los procesos de definición de unas políticas de seguridad alimentaria nacionales.

La presencia de algunos aspectos de la definición de soberanía alimentaria en las Directrices voluntarias de la FAO y en la Observación 12 aunque sea con matices, es sólo un ejemplo de la importancia que está tomando este movimiento para escapar del hambre en la cooperación bilateral y multilateral. Así Jean Ziegler considera la soberanía alimentaria como un «modelo alternativo para la agricultura y el comercio de productos agrícolas a fin de cumplir las obligaciones de los Estados de respetar, proteger y hacer efectivo el derecho a la alimentación» ${ }^{15}$. Así mismo, la Estrategia de Lucha contra el Hambre de la Cooperación Española está teniendo en cuenta el enfoque soberanista.

${ }^{15}$ Informe del Relator Especial sobre el derecho a la alimentación, Jean Ziegler, presentado de conformidad con la resolución 2003/25 de la Comisión de Derechos Humanos (2004) párrafo 54. 
Desatender las reivindicaciones de los movimientos que están dentro de la soberanía alimentaria es romper el enfoque de derechos desde el principio. Pero debemos tener en cuenta algunas apreciaciones. Cada Estado no se debe apropiar del concepto de soberanía alimentaria ignorando las demandas de su propia ciudadanía. Estos son los titulares de derecho en toda su diversidad y bajo los principios de no discriminación y acceso universal. Tampoco los Estados se deben apropiar de la soberanía alimentaria desde un punto de vista ideológico contra otros Estados.

\section{Interacciones entre los marcos}

Hemos repasado rápidamente la evolución y concepto de derecho a la alimentación, seguridad alimentaria y soberanía alimentaria viendo como son tres conceptos diferentes, necesarios y complementarios si buscamos la erradicación del hambre.

El derecho a la alimentación es el marco legal que expone las responsabilidades de los Estados y la reclamación y reparación de las víctimas. Pertenece a la esfera de la justicia en el derecho internacional de los derechos humanos y en la legislación nacional. Como las causas del hambre no son las mismas en Guatemala que en Etiopía, las leyes nacionales deben atender a las peculiaridades geopolíticas y a la diversidad para ganar eficiencia y eficacia.

La seguridad alimentaria es el marco técnico en la esfera de políticas de cooperación internacional y gubernamentales para la buena gestión de los instrumentos necesarios para escapar del hambre. Este marco no sólo pertenece a la esfera internacional de la cooperación sino a la nacional, ya que los gobiernos deben ser agentes activos de un desarrollo endógeno.

La soberanía alimentaria es un marco social al ser su esfera la de la población civil y movimientos sociales. Debemos considerar que cuando un proyecto de seguridad alimentaria respeta lo endógeno y fomenta procesos de aprendizaje y acción participativos, como el diagnóstico rural participativo surgiendo las decisiones de la comunidad y respetando usos y costumbres, estamos en un proceso soberanista aunque tenga asistencia técnica externa. Incluye otras problemáticas como el derecho a la tierra o el papel de la OMC. (gráfico 3).

Cuando el marco legal es lento y arduo y las políticas de seguridad alimentaria no han conseguido erradicar el hambre, es necesaria la unión de los movimientos sociales para conseguir políticas más justas emanadas de los más vulnerables, de 
aquellos que concentran más el hambre (familias campesinas y asalariados sin tierra) frente a la globalización excluyente y la especulación alimentaria.

Aunque tradicionalmente estos tres marcos con sus respectivas esferas han actuado a las espaldas entre sí, están abocados a interactuar sinérgicamente. Las categorías del derecho a la alimentación deben definir las políticas de seguridad alimentaria mediante el afianzamiento de la justiciabilidad a nivel internacional y la creación y modificación a nivel nacional. La interacción entre derecho a la alimentación y seguridad alimentaria es sencilla: la creación de políticas públicas.

A su vez, la esfera de la cooperación y los gobiernos deben formar, sensibilizar y empoderar a la sociedad civil para concienciar de las problemáticas del hambre. Aquí entra la sinergia del movimiento soberanista, de modo que las políticas de seguridad alimentaria nacionales no vengan aplicadas desde el exterior o bajo los intereses de los gobiernos, sino que estén definidas desde las propias necesidades y cultura endógena, toda vez que son ellos los titulares de derechos. Por otro lado a todos los actores de las esferas les corresponde informar a la población de sus derechos para reivindicarlos a nivel nacional e internacional cuando se vean violados y para que las leyes nacionales se ajusten a sus necesidades. En este sentido la participación debe sobrepasar el carácter informante o consultivo para adentrarse en todo el proceso de decisiones.

Las tres esferas descritas deben modificar su modo de acción para que se redistribuya el poder y no presentar al debate proyectos ya decididos a nivel metodológico o práctico, porque esto es una ilusión de participación. Sólo desde esta perspectiva es posible crear un espacio común de interacción que haga posible un escenario de acciones participativas crecientes, es decir una auténtica cooperación. Se sustituye la "radicalidad del purismo" de los movimientos sociales hacia las estructuras de poder, al "poder de lo ajeno o insular" que tradicionalmente ha caracterizado a la legislación y al "poder de la imposición u opresión" de gobiernos y la cooperación bilateral o multilateral para crear un "poder de la cooperación" que aúne a estos tres marcos con sus respectivas esferas.

La interacción de marcos y esferas en la lucha contra el hambre sólo puede desarrollarse desde el diálogo democrático, es decir desde una democracia inclusiva y participativa, que va más allá de las elecciones, para formar verdaderos espacios de diálogo que posibiliten pactos sociales entre el gobierno y la sociedad civil en el marco del derecho internacional de los derechos humanos.

Las sinergias son posibles porque dependen de la voluntad de los actores implicados. Sólo hace falta una puesta en común que establezca planes de trabajo 
sostenibles, partiendo de un mapeo teórico. Esbozando un poco lo que debería ser este mapeo, vamos a cotejar brevemente las cuatro líneas de acción de la soberanía alimentaria ${ }^{16}$, con las Directrices Voluntarias de la FAO y la Observación 12 sobre el derecho a la alimentación, para ver en el plano teórico cuales son los lugares comunes que permitirían una interacción.

I. Derecho a la alimentación: promover la adopción de políticas de alimentación y agricultura con un enfoque basado en derechos que conducirán a la terminación de la violación del derecho a la alimentación adecuada y reducirán, y eliminarán progresivamente, el hambre y la desnutrición. Este derecho es ahora reconocido como un derecho individual.

Este punto fluctúa en todas las Directrices voluntarias, especialmente se advierte en la introducción las obligación de los Estados partes y en la directriz 1.

Como vimos en la Observación 12, los Estados partes tienen la obligación de adoptar medidas progresivas para la aplicación del derecho a la alimentación, garantizando un acceso mínimo a los alimentos (párrafo 14).

II. Acceso a recursos productivos: promover el acceso continuo de los productores de pequeña escala, pastores, pescadores artesanales y pueblos indígenas al uso sostenible de sus tierras, aguas, recursos genéticos y otros recursos naturales utilizados para la alimentación y producción agrícola, y a compartir equitativamente los beneficios derivados de su uso. Una reforma agraria genuina es necesaria, que adjudique a las personas sin tierra y a los productores, especialmente a las mujeres, la propiedad y el control sobre la tierra que trabajan y que devuelva sus territorios a los pueblos indígenas.

La directriz 8 está dedicada al acceso de recursos y bienes: mercado laboral, tierra, agua, recursos genéticos para la agricultura y la alimentación, sostenibilidad y servicios $^{17}$. Con atención a los pueblos indígenas (párrafos 8.1 , 8.10 y 8.12).

Según la Observación 12 los Estados partes tienen la «obligación de respetar el acceso existente a una alimentación adecuada requiere que los Estados no adopten medidas de ningún tipo que tengan por resultado impedir ese acceso» (párrafo

${ }^{16}$ WINDFUHR, M. Y JONSÉN, J. (2005) pp. 16-17.

17 Actualmente la FAO está elaborando unas directrices voluntarias sobre la gobernabilidad de la tierra y los recursos naturales. 
15), sin meterse en excesivas disquisiciones referidas al derecho a la tierra, agua, etc. salvo en el acceso equitativo en el caso de la mujer (párrafo 26). Se alude a los indígenas como población vulnerable cuyas tierras ancestrales pueden verse amenazadas (párrafo 13).

III. Producción agroecológica dominante: promover modelos agroecológicos familiares y comunitarios de producción de alimentos, en la práctica y a través de políticas, investigación y desarrollo, a fin de ayudar a garantizar la seguridad alimentaria de los pueblos, especialmente de aquellos que son vulnerables al hambre y la desnutrición, por medio de la gestión sostenible de agroecosistemas locales para la producción de alimentos predominantemente para mercados locales.

La directriz 2 habla de políticas de desarrollo económico orientadas a comunidades rurales pobres y vulnerables. La directriz 13 apoya a los grupos vulnerables. La alusión a modelos agroecológicos está en la «utilización sostenible de los recursos genéticos para la alimentación y la agricultura, y en particular, en su caso, para proteger los conocimientos tradicionales pertinentes» (párrafo 8.12).

La Observación 12 afirma: "hay que procurar gestionar y utilizar de modo más sostenible los recursos alimentarios naturales y de otro tipo en los niveles nacional, regional, local y doméstico» (párrafo 25). También podemos ligar este punto al concepto de "adecuación" de la Observación 12 al poner de relieve una serie de factores como el ecológico (párrafo 7).

IV. Comercio y mercados locales: promover políticas de comercio equitativas que les permitan a las comunidades y a los países vulnerables al hambre y a la desnutrición la producción de cantidades suficientes de suministros de alimentos inocuos y seguros. Políticas que militen en contra de los efectos negativos de las exportaciones subvencionadas, del dumping de alimentos, de los precios artificialmente bajos y de otros elementos semejantes que caracterizan el modelo actual de comercio agrícola.

La directriz 4 es la que se encarga de los sistemas de mercado. Se aconseja seguir sistemas comerciales que garanticen la seguridad alimentaria. En el párrafo 4.4. habla de «respetar los acuerdos de la Organización Mundial del Comercio (OMC)», diciendo que se esfuerce en cumplir los acuerdos de Doha: mejoras sustanciales del acceso a los mercados, reducir todas las formas de subvenciones a la exportación y reducciones de la ayuda interna (párrafos 6 a 10). 
La alusión al comercio de la Observación 12 está en el párrafo 39: «la asistencia alimentaria debe prestarse, en la medida de lo posible, de modo que no afecte negativamente a los productores locales y a los mercados locales [...] Los productos que figuren en el comercio internacional de alimentos o en los programas de asistencia deben ser sanos y ser aceptables culturalmente para la población receptora».

Estas relaciones y lugares comunes deben ser la base para la construcción de indicadores, para la interacción y el diálogo. Y se pueden hacer en varios mecanismos de protección o espacios que relatamos a continuación.

\section{Mecanismos de protección}

Hay diversos espacios donde estas interacciones se pueden llevar a cabo. Los mecanismos de protección son los instrumentos que se utilizan para la implementación, defensa y reparación de cualquier derecho, en nuestro caso del derecho a la alimentación.

Jurisdicción nacional: más allá de los marcos legales internacionales, se debe asegurar que el derecho a la alimentación esté debidamente consagrado en la legislación nacional. En la Constitución la alimentación debe estar consagrada como derecho fundamental y debe expresar que asume la legislación internacional ratificada. Esto se debe desarrollar mediante leyes de seguridad alimentaria y nutricional. Aquí entran normas, leyes y decretos que desarrollen y den contenido al citado derecho.

Política pública: es el punto en el que los gobiernos declaran cómo deben de desarrollarse las distintas intervenciones dirigidas a garantizar el derecho a la alimentación. Tienen como referente el punto anterior y deben ser incluyentes, transparentes y participativas. Para definir los presupuestos, se hará el uso del máximo de recursos nacionales y si no fueran suficientes, se hará uso de la cooperación internacional.

Exigibilidad-Justiciabilidad: hay un escenario adecuado para la exigibilidad del derecho, desde la participación y presión política por parte de la sociedad civil hasta el acceso sin discriminación de todos los titulares del derecho a un juicio, en el caso de violación del derecho. La jurisprudencia es un buen medio para interpretar y aplicar las leyes. 
Otros mecanismos: recursos administrativos: en la mayoría de los sistemas jurídicos existen estos recursos que permiten a los ciudadanos presentar directamente ante la autoridad competente una solicitud para la realización de alguna actividad por parte de esta (cobertura alimentaria, acceso indiscriminado a la tierra, etc.), o bien para el cese de cualquier actividad que pueda ser violatoria de derechos (hambre como arma de guerra, etc.). Algunos ejemplos de estos mecanismos son el derecho de petición y los recursos de reposición, apelación y queja. Reclamaciones de las Comisiones, Procuradurías o Defensorías de los DDHH. Así en Brasil, el Ministerio Público puede presentar Acciones Públicas en defensa de víctimas de todos los DDHH y en Colombia la Defensoría del Pueblo puede presentar acciones de tutela para la defensa de víctimas de todos los DDHH.

A continuación vamos a detenernos con más detalle en el mecanismo de Justiciabilidad y en el de Políticas Públicas. Ambas se pueden trabajar desde el concepto de "metaderecho" (más allá del derecho) propuesto Amartya Sen ${ }^{18}$. Es decir ya no sólo hablamos del derecho a la alimentación, sino del derecho a no sufrir hambre (derecho alimentario básico) y el derecho a una alimentación adecuada (derecho alimentario cualificado).

\subsection{Políticas públicas alimentarias}

Una política pública es un proyecto con unos objetivos, medios y acciones en los que está implicada total o parcialmente una institución gubernamental, orientando el comportamiento de actores individuales o colectivos para modificar una situación problemática o insatisfactoria. Unas políticas públicas es una manera de operativizar las líneas dadas por los marcos jurídicos dentro de un Estado democrático.

La construcción de una política pública es un proceso dinámico y competitivo, donde tiene importancia la capacidad de incidencia política de la sociedad civil para visibilizar un problema que traducido en soluciones beneficien al conjunto de la población - a una parte de la misma, en el caso de políticas públicas focalizadas.

Las tres agencias de Naciones Unidas que trabajan sobre la agricultura y la alimentación -FAO, Programa Mundial de Alimentos (PMA) y Fondo Internacional para el Desarrollo de la Agricultura (FIDA)- proponen que las políticas públicas para erradicar el hambre y la desnutrición deberían articularse en torno a una

18 Sen, A. (2002). 
"Doble Vía de Actuación" (emergencial y estructural)19, tanto a nivel temporal como en cuanto a grupos meta y, por tanto, a tipos de actividades. La selección, priorización y ejecución de actividades en el marco de esta doble vía dependerá del perfil nutricional, epidemiológico y socioeconómico de cada país, de las prioridades políticas y de los programas nacionales que están en curso.

La vía de emergencia enfoca sus esfuerzos en los efectos del hambre (en particular la desnutrición) y enfatiza intervenciones nutricionales directas y de salud, incidiendo directamente sobre el acceso directo a los alimentos a través del establecimiento y reforzamiento de redes de protección social que garanticen un acceso inmediato a los alimentos para aquellos ciudadanos que no tienen garantizado ese derecho, con el fin de asegurar al menos su derecho a seguir viviendo. Además, es el reconocimiento de que los hambrientos no pueden esperar. Aquí el derecho a la alimentación está tomado como un derecho fundamental, ya que apela al mínimo vital, a la vida y a la vida con dignidad. Estaría dentro del derecho alimentario básico y respondería a asegurar inmediatamente el derecho a la alimentación.

Algunas intervenciones de esta vía pueden ser:

I. Suministrar suplementos alimentarios y promover su consumo entre las mujeres embarazadas y lactantes, así como los infantes y niños de edad preescolar.

II. Instituir v optimizar sistemas de protección alimentaria de emergencia en casos de desastres naturales y conflictos sociales, garantizando el apoyo directo para los niños y sus madres.

III. Mantener y mejorar los programas de fortificación de alimentos con micronutrientes, los cuales han mostrado ser muy efectivos para reducir las brechas en la salud, el aprendizaje y la productividad.

IV. Promover la lactancia materna (exclusiva hasta los seis meses de edad), brindando condiciones apropiadas para las madres trabajadoras.

V. Promoción de bancos de alimentos y comedores populares.

VI. Subvenciones a alimentos esenciales de la canasta básica alimentaria.

\footnotetext{
${ }^{19}$ El enfoque de doble vía fue presentado por primera vez por FAO, PMA y FIDA en la Conferencia Internacional sobre la Financiación para el Desarrollo, realizada en Monterrey, (México) y confirmado posteriormente durante la Cumbre Mundial de la Alimentación: cinco años después (Roma, 2002).
} 
La vía de estructura incorpora a todas aquellas acciones que buscan garantizar que todos los hogares tengan acceso a los medios necesarios para producir el alimento que necesitan o puedan tener los ingresos necesarios para adquirir dichos alimentos. Estas acciones están vinculadas a políticas públicas que demandan mayor presupuesto y una mayor coordinación de actores y suponen, en muchos casos, un notable cambio en las estructuras de producción económica de los países. Esta vía persigue la creación de una institucionalidad que asegure la sostenibilidad de largo plazo en la lucha contra el hambre. Estas políticas deben contar tanto con una fuerte voluntad política como con un amplio respaldo social. Aquí el derecho a la alimentación está tomado como un DESC, con una realización progresiva y un carácter prestacional. Estaría dentro del derecho alimentario cualificado y respondería a asegurar progresivamente el derecho a la alimentación.

Algunas intervenciones de esta vía pueden ser:

I. El reforzamiento de la institucionalidad de la seguridad alimentaria, estableciendo leyes y Programas Nacionales de seguridad alimentaria y erradicación de la desnutrición crónica, que garanticen una sostenibilidad en la lucha contra el hambre.

II. El fomento del trabajo estable y de la productividad a través del apoyo a las actividades agrícolas y no agrícolas, del fomento del empleo en áreas urbanas y rurales.

III. La revitalización de los sistemas de extensión horizontal y la investigación agrícola a fin de satisfacer las necesidades de los pequeños agricultores que viven en peores condiciones, en un marco de mercados desregularizados.

IV. La promoción y mejora de las prácticas de consumo de alimentos basadas en productos locales y tradicionales muy nutritivos, teniendo en cuenta las diversidades culturales y étnicas.

V. El fortalecimiento de programas de información pública en educación, alimentos y nutrición y comunicación de mejores prácticas en cuidado de los niños y niñas, higiene, eliminación de parásitos, hábitos alimentarios saludables, y manejo y conservación de alimentos, orientadas hacia los grupos más vulnerables.

VI. Apoyo a la agricultura familiar, a través de líneas de crédito, compras focalizadas, subsidios en productos agropecuarios, etc. 
Se habrá visto que ambos grupos están en consonancia con los dos objetivos marcados por el CFA y con los cuatro temas que han interactuado en el apartado anterior. El repertorio de actividades de ambos grupos se pueden trabajar integradamente en el marco del derecho a la alimentación, la asistencia técnica de la seguridad alimentaria y el enfoque participativo y local de la soberanía alimentaria. El primer grupo de programas emergenciales se puede considerar un subconjunto de las Políticas y Programas Sociales, más específicamente denominados Programas de Asistencia Alimentaria o Redes de Protección Social. Implementa el sentido más básico de la realización del derecho a la alimentación y cuenta con la protección del Estado frente a situaciones de extrema vulnerabilidad. El segundo grupo de programas, de la vía estructural, puede considerarse como un subconjunto de desarrollo productivo o, en el nivel macroeconómico, como aquellas políticas que promueven el crecimiento económico de áreas rurales y las conexiones entre áreas rurales y urbanas. Implementa en desarrollo el derecho a la alimentación estableciendo medidas estructurales por parte del Estado en la productividad, atención a carencias básicas y en mayor profundidad a otros sectores implicados como la salud o la educación.

\subsection{Justiciabilidad del Derecho a la Alimentación}

La justiciabilidad es la posibilidad de que un derecho sea invocado por una persona - grupo de personas ante los tribunales de justicia con el fin de que se adopten las medidas necesarias para su efectivo disfrute y ejercicio. La justiciabilidad hace referencia exclusivamente a una estrategia de exigibilidad de derechos a través de la vía judicial. En palabras de José Bengoa es «el proceso por medio del cual los derechos establecidos en los Pactos Internacionales de Derechos Humanos y otros instrumentos puedan ser reclamados efectivamente frente a los tribunales de justicia, los organismos públicos y aplicada la justicia como en cualquier otro caso de derecho vulnerado» ${ }^{20}$.

Todos los derechos son exigibles pero no judiciables. Para ganar en justiciabilidad se creó la figura del Protocolo Facultativo. Es un procedimiento semijudicial de quejas individuales que puede tratar el Comité de Derechos Humanos de la ONU. Los Estados que lo ratifican permiten a sus ciudadanos solicitar del Comité un análisis sobre presuntas violaciones. Este procedimiento está dividido en dos fases:

${ }^{20}$ La relación entre el Disfrute de los Derechos Humanos, en particular los derechos económicos, sociales y culturales, y la distribución de los ingresos. Informe final preparado por el Sr. José Bengoa, Relator Especial (1997) párrafo 84. 
la admisibilidad del caso una vez agotados los recursos judiciales nacionales, el dictamen y recomendaciones que obligan a los Estados a reparar a las víctimas. El referido al Pacto Internacional de Derechos Civiles y Políticos se creó en 1966, pero el del Pacto Internacional de Derechos Económicos Sociales y Culturales (PIDESC) no se aprobó hasta el 10 de diciembre de 2008. Entrará en vigor cuando sea ratificado por 10 Estados parte y como ya hemos visto, uno de los derechos que se podrán justiciabilizar será el de la alimentación. Hasta la fecha lo han ratificado Ecuador, España y Mongolia.

Mientras el protocolo entra en vigor, el órgano supervisor del PIDESC es el Consejo económico y social de la ONU (ECOSOC), que creó el Comité de Derechos Económicos, Sociales y Culturales en 1985 para revisar los informes que los Estados firmantes están obligados a presentar con carácter periódico y en los cuales se informa del cumplimiento y obstáculos que encuentran en la realización de estos derechos.

El problema es que sólo entran dentro de este sistema los Estados parte que han ratificado el PIDESC. De cualquier modo con este nuevo instrumento caen muchos mitos y prejuicios ante los derechos económicos, sociales y culturales: su separación de los derechos civiles y políticos, su elevado coste económico o su realización progresiva y a largo tiempo, sin duda construcciones ficticias de interés político.

Por ello es importante que la justiciabilidad del derecho a la alimentación se aplique también en el ámbito regional y en el nacional. Jurídicamente el tratamiento del derecho es doble: a no tener hambre "derecho alimentario básico" y el derecho a una alimentación adecuada, "derecho alimentario cualificado". Esto se corresponde con el enfoque de doble vía: el derecho a estar libre de hambre desarrollado en políticas públicas a través de la vía de la emergencia, y el derecho a una alimentación adecuada desarrollado en políticas públicas a través de la vía estructural. La primera se encarga del acceso inmediato y la segunda se encarga de la disponibilidad, inocuidad biológica, la aceptabilidad cultural y la sostenibilidad. De este modo la justiciabilidad no sólo se corresponde con las leyes existentes sino con la aplicación de las políticas públicas.

En el ámbito judicial se reconoce que el derecho no es compresible únicamente desde su visión cualificada que lo clasifica como derecho prestacional. Es decir, éste debe ser entendido igualmente desde el ámbito básico de protección, como sería el derecho social fundamental de estar libre de hambre.

La jurisprudencia se ha pronunciado en varias ocasiones siguiendo las líneas expuestas. A nivel regional, la Corte Interamericana de Derechos Humanos emitió 
una sentencia el 29 de marzo de 2006 en la cual se fallaba contra Paraguay. Se condenaba al Estado por la violación de los derechos a la propiedad, a las Garantías Judiciales, a la Protección Judicial, además del derecho a la vida y el derecho a la personalidad jurídica de los miembros de la comunidad indígena Enxet de Sawhoyamaxa. Uno de los artículos centrales de la sentencia dictada se relaciona con el fallecimiento por enfermedades derivadas del hambre y desnutrición de 18 niños y niñas miembros de la comunidad Enxet de Sawhoyamaxa, violando el derecho a la vida. La condena consideró que las muertes de los menores indígenas son atribuibles al Estado (falta de voluntad), por ello deberá efectuar un pago compensatorio a las víctimas en concepto de daño inmaterial, costas y gastos. La sentencia se revisa periódicamente por la Corte competente para analizar su grado de cumplimiento por parte del Estado.

A nivel nacional, el Tribunal Supremo de la India aceptó en 2001 el pleito de una ONG de Rajastán, obligando al Estado a utilizar las existencias alimentarias del país para prevenir una amenaza de hambruna durante una sequía generalizada. El órgano competente ha emitido varias órdenes provisionales significativas que han tenido el efecto de reconocer formalmente el derecho a la alimentación, tales como ordenar al Gobierno central y a los gobiernos de los Estados que gastasen recursos para mejorar la situación alimentaria del campesinado en la región. El Tribunal ordenó asimismo a los gobiernos que informaran a las poblaciones interesadas de su derecho legal a la alimentación. Estas órdenes han derivado en políticas públicas con programas de almuerzos escolares en la India, obligatorio para todos los niños matriculados en escuelas primarias públicas o financiadas por el gobierno. Se trata del mayor programa de comidas escolares del mundo, ya que actualmente se sirven más de 50 millones de comidas cocinadas al día.

Otros elementos que hacen factible la justiciabilidad del derecho a la alimentación es la Constitución. El caso de Brasil es especialmente significativo. Los esfuerzos en apoyo del derecho a la alimentación comenzaron con la primera Conferencia Nacional sobre la Alimentación y la Nutrición en 1986, que fue parte del proceso de redacción de la nueva Constitución. La sociedad civil participó activamente y la consagración del derecho a la alimentación en la Constitución permitió su justiciabilidad y el desarrollo de una ley de seguridad alimentaria en 2006. Esta da un marco legal al programa Hambre Cero, iniciativa de 2003 del presidente Lula da Silva que subraya la importancia de la voluntad política. El programa combina 31 medidas aplicadas por diversos ministerios, encaminadas a garantizar el acceso a la alimentación, aumentar los ingresos familiares y promover las explotaciones agrícolas familiares, desde acciones emergenciales hasta estructurales. Incluye el Consejo Nacional de Seguridad Alimentaria y Nutricional, que rinde cuentas direc- 
tamente a la Presidencia, cuyo cometido es asesorar sobre las políticas y directrices necesarias para realizar el derecho a la alimentación; un sistema de vigilancia que permite seguir la evolución del hambre y la malnutrición; una comisión que vigila las violaciones del derecho a la alimentación; y el Ministerio Público, independiente de las tres ramas del Gobierno y con poder para proponer medidas jurídicamente vinculantes a fin de remediar las violaciones de los derechos humanos.

La red "Acción ciudadana", que se ocupa del hambre, la pobreza y la exclusión social, ha creado más de 7000 comités locales para realizar proyectos que van desde la creación de huertos urbanos hasta el apoyo a la reforma agraria. Más de 1000 grupos de la sociedad civil prepararon informes para el $30^{\circ}$ período de sesiones del Comité de Derechos Económicos, Sociales y Culturales, celebrado en 2003. La combinación de una política gubernamental progresista y una sociedad civil proactiva ha permitido lograr una amplia aceptación en Brasil de la legitimidad del derecho a la alimentación. Los datos nos hablan de un mayor acceso a tierras, mayor rendimiento de los cultivos o de la reducción de la mortalidad infantil por causas de desnutrición en un $22 \%{ }^{21}$.

Este programa es el ejemplo de cómo bajo el marco del derecho a la alimentación se pueden tomar los principios de la seguridad alimentaria desde la soberanía alimentaria, desarrollados participativamente en políticas públicas inclusivas y asegurando su justiciabilidad.

\section{Conclusiones y recomendaciones}

En este artículo hemos hecho un repaso por los marcos (herramientas) y esferas (actores) implicados en la lucha contra el hambre. Se han mostrado algunos de los puntos en común que pueden trabajarse en mecanismos de protección (espacios) para construir una nueva gobernanza de la seguridad alimentaria. Llevarla a cabo a nivel global está siendo complicado, por los intereses contrapuestos de los distintos países y la pérdida de poder de la FAO ante otros organismos como el Banco Mundial o la OMC.

Por esta razón hemos propuesto soluciones legales y políticas a nivel nacional. Un modelo de interacción a nivel nacional y siempre bajo un enfoque de derechos puede dar resultados más efectivos, como hemos visto en Brasil, en una tendencia que se retroalimenta de la justiciabilidad del derecho a la voluntad política.

${ }^{21}$ www.rlc.fao.org/es/prioridades/seguridad/fomezero/ 
Los casi 1000 millones de hambrientos y desnutridos en el mundo han demostrado el fracaso de los proyectos exclusivamente técnicos para erradicar el hambre. Por ello esta crisis contra la dignidad humana es una oportunidad de ser osados. Es necesario introducir en nuestros diccionarios el verbo transitivo "replantear" en clave de derechos, aunque todo ello suponga salir del camino tradicionalmente marcado. Como decía Albert Einstein: "no pretendamos que las cosas cambien, si siempre hacemos lo mismo". Parece que todas las cumbres y reuniones a nivel mundial, producidas especialmente en los tres últimos años no están cambiando sustancialmente la situación. La crisis nos obliga a volver a pensar desde un enfoque de derechos en la justiciabilidad, el fortalecimiento institucional y la reestructuración del sistema alimentario de lo internacional a lo nacional en base a los siguientes términos:

I. Recuperar las competencias en alimentación y agricultura de la FAO, frente a las organizaciones de Bretton Woods o la OMC.

II. Coordinar programas con otras agencias de la ONU como la Organización Mundial de la Salud u ONU Mujer debido al carácter multisectorial del hambre y la desnutrición.

III. Renovar el Comité de Seguridad Alimentaria de la FAO, fundamentado en toda la normativa existente en torno al derecho a la alimentación.

IV. Centrar esfuerzos en la promoción de la seguridad alimentaria y nutricional a nivel nacional.

V. Incorporar a la sociedad civil en las decisiones referentes a la seguridad alimentaria y nutricional y promover una participación en las decisiones más allá de la consulta.

VI. Apoyar la creación de leyes de seguridad alimentaria y nutricional que promuevan la justiciabilidad y rendición de cuentas mutua del derecho a la alimentación.

VII. Demandar que los gobiernos ratifiquen el Protocolo Facultativo del PIDESC.

VIII. Construir políticas públicas en las vías emergencial y estructural que implementen el derecho a la alimentación desde las categorías de disponibilidad, accesibilidad, aceptabilidad, calidad, participación y sostenibilidad. 
IX. Aplicar un enfoque de derechos en todas estas políticas y programas que emane desde los titulares de derechos en base a su dignidad innata y al principio de igualdad y no discriminación contemplando el género, la etnia, etc. centrándose en las personas más vulnerables, excluidas o en riesgo de exclusión.

X. Seguir las directrices voluntarias de la FAO y ampliarlas en la utilización de recursos productivos: agua, tierra, semillas, etc. y de todos los sectores que entran en juego para lograr una alimentación adecuada.

XI. Informar a los titulares de derechos de su derecho legal a la alimentación, apoyar a los titulares de obligaciones en la gobernanza nacional de la seguridad alimentaria y regular a los titulares de responsabilidades.

XII. Crear observatorios nacionales de seguridad alimentaria y nutricional que reporten al Comité de Seguridad Alimentaria el grado de cumplimiento del derecho a la alimentación.

XIII. Impedir la importación de alimentos que afecten la producción, distribución y comercialización de alimentos de producción interna.

XIV. Priorizar a nivel local la producción de alimentos para el autoconsumo y los mercados locales.

$\mathrm{XV}$. Fomentar la agricultura familiar, cría de especies menores y agricultura urbana. 


\section{Cuadros y gráficos}

\section{GRÁFICO I}

Número de personas que padecen hambre en el mundo (millones)

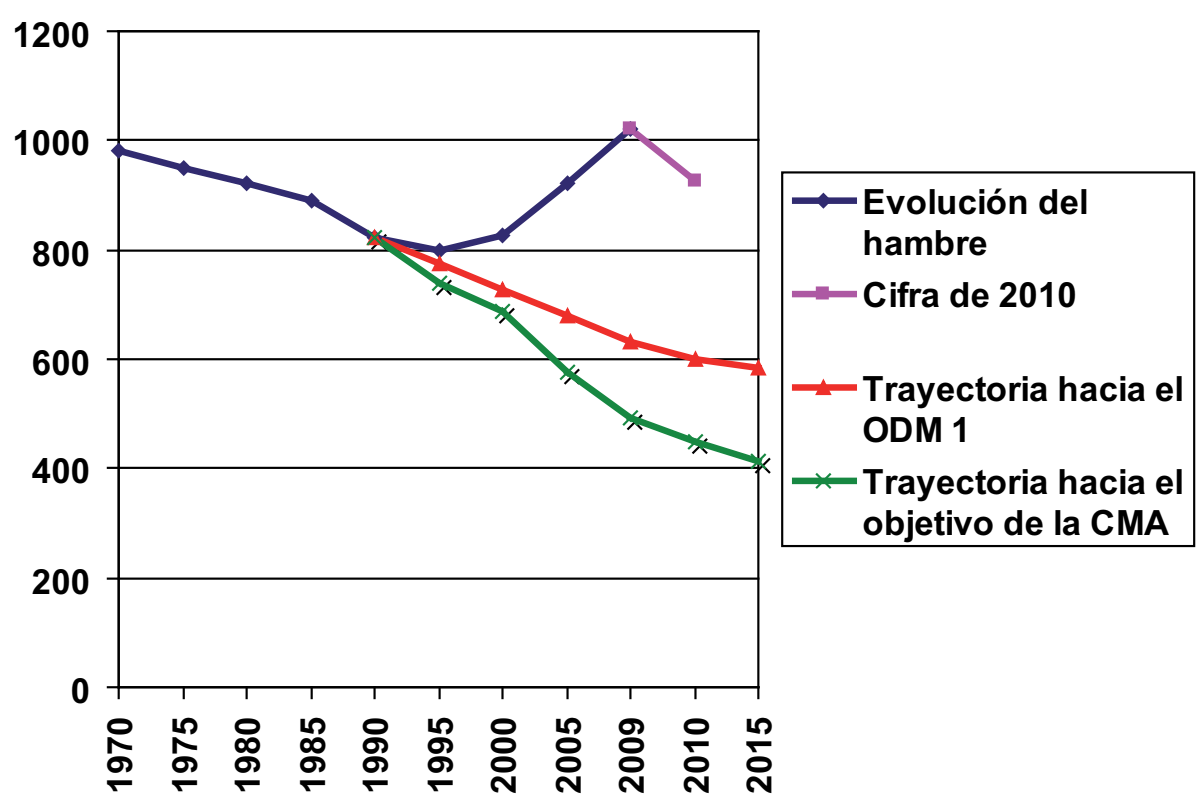

Elaboración propia sobre datos de los SOFI de la FAO. 


\section{CUADRO I \\ Plan de acción de la Cumbre Mundial de la Alimentación 2002}

1. Garantizaremos un entono político, social y económico propicio, destinado a crear las mejores condiciones posibles para la erradicación de la pobreza y para la paz duradera, sobre la base de una participación plena y equitativa de las mujeres y los hombres, que favorezca al máximo la consecución de una seguridad alimentaria sostenible para todos.

2. Aplicaremos políticas que tengan por objeto erradicar la pobreza y la desigualdad y mejorar el acceso físico y económico de todos en todo momento a alimentos suficientes, nutricionalmente adecuados e inocuos, y su utilización efectiva.

3. Nos esforzaremos por adoptar políticas y prácticas participativas y sostenibles de desarrollo alimentario, agrario, pesquero, forestal y rural, en zonas de alto y bajo potencial, que sean fundamentales para asegurar un suministro de alimentos suficiente y fiable a nivel familiar, nacional, regional y mundial y que combatan las plagas, la sequía y la desertificación, considerando el carácter multifuncional de la agricultura.

4. Nos esforzaremos por asegurar que las políticas de comercio alimentario y agrícola y de comercio en general contribuyan a fomentar la seguridad alimentaria para todos a través de un sistema de comercio mundial leal y orientado al mercado.

5. Nos esforzaremos por prevenir y estar preparados para afrontar las catástrofes naturales $y$ emergencias de origen humano, y por atender las necesidades transitorias y urgentes de alimentos de maneras que fomenten la recuperación, la rehabilitación, el desarrollo y la capacidad para satisfacer las necesidades futuras.

6. Promoveremos la asignación y utilización óptimas de las inversiones públicas y privadas para fortalecer los recursos humanos, los sistemas alimentarios, agrícolas, pesqueros y forestales sostenibles y el desarrollo rural en zonas de alto y bajo potencial.

7. Aplicaremos, vigilaremos y daremos seguimiento a este Plan de Acción a todos los niveles en cooperación con la Comunidad Internacional.

Fuente: Cumbre mundial de la alimentación: cinco años después (2002). 


\section{GRÁFICO 2}

Dimensiones de la inseguridad alimentaria

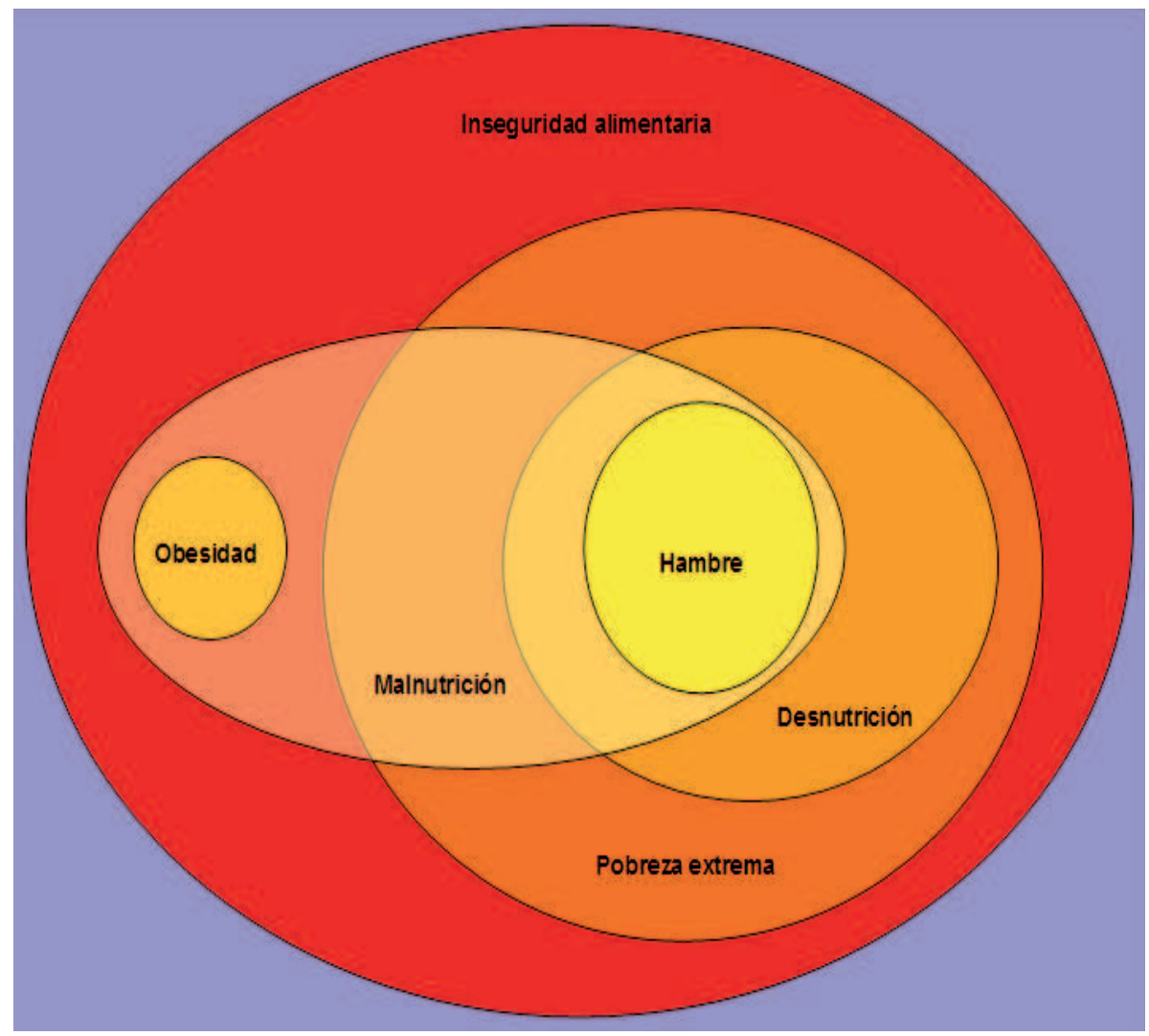

Fuente: Da Silva, J. G., TAKAGI, M. y Del Grossi, M. E. (2006): p. 184 con aportaciones propias. 


\section{GRÁFICO 3 \\ Interacciones entre marcos y esferas en la lucha contra el hambre}

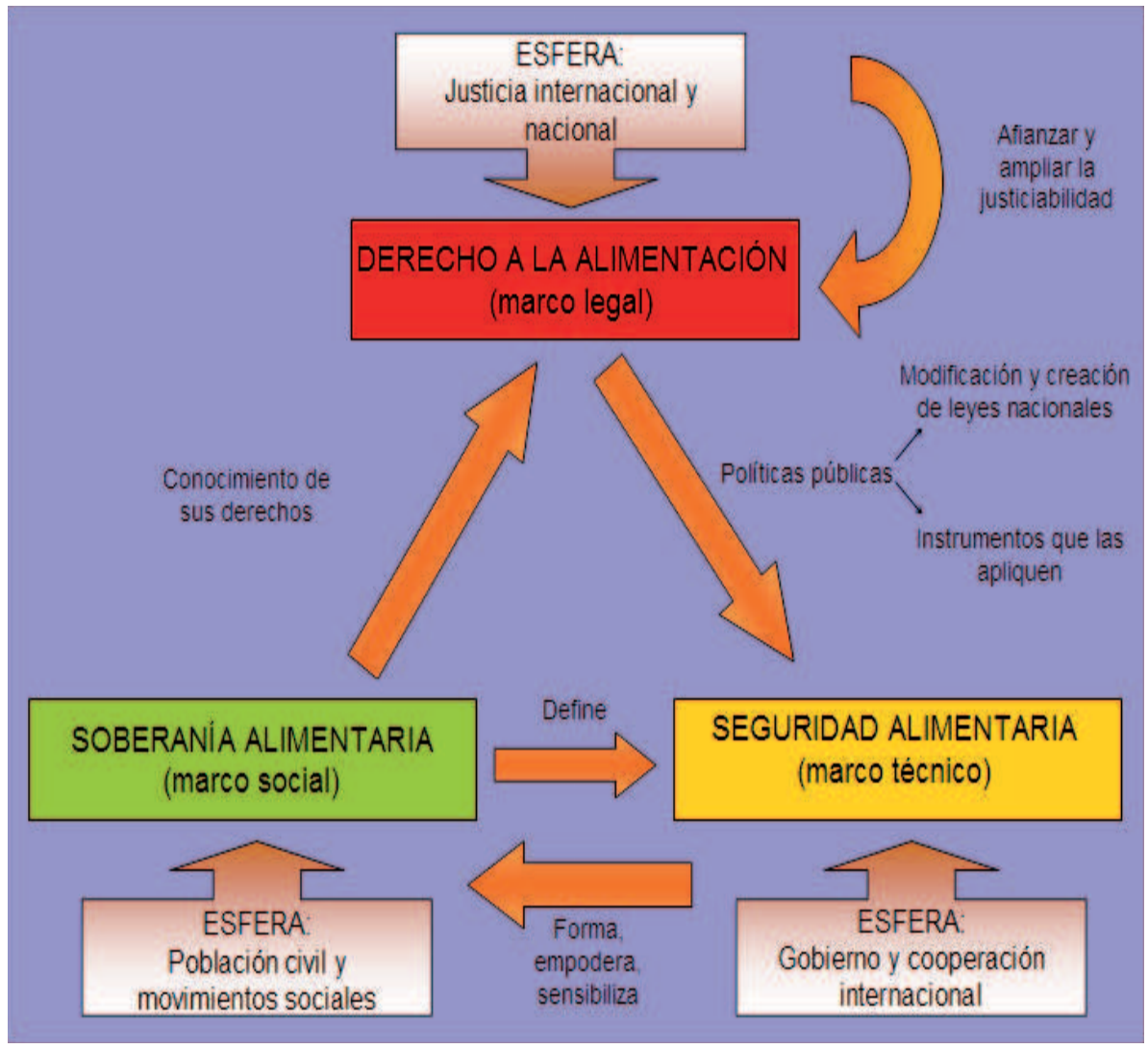

Elaboración propia. 


\section{Bibliografía}

BANCO MUNDIAL (1986) La pobreza y el hambre. Temas y opiniones sobre la seguridad alimentaria en los países en desarrollo. Washington D.C., B.M.

BINDRABAN, P. S.; Brouswer, I. D. y Moll, H. A. (2006) "Hacia las estrategias nacionales de seguridad alimentaria y reducción de la pobreza: la necesidad de la capacidad de desarrollo y atención internacional". CEHAP (2006) Seguridad alimentaria y políticas de lucha contra el hambre. Seminario Internacional sobre Seguridad Alimentaria y Lucha contra el Hambre. Córdoba, Oficina de Cooperación Internacional de Desarrollo de la Diputación de Córdoba. Servicio de Publicaciones de la Universidad de Córdoba, pp. 61-86.

Da Silva, J. G., TAKagl, M. y Del Grossi, M. E. (2006) La política de seguridad alimentaria y nutricional de Brasil a partir del programa "Hambre Cero". CEHAP (2006) Seguridad alimentaria y políticas de lucha contra el hambre. Seminario Internacional sobre Seguridad Alimentaria y Lucha contra el Hambre. Córdoba, Oficina de Cooperación Internacional de Desarrollo de la Diputación de Córdoba. Servicio de Publicaciones de la Universidad de Córdoba, pp. 181-205.

De Loma-Ossorio, E. y LAHOz, C. (2004) Seguridad alimentaria y nutricional. Conceptos básicos. Tegucigalpa, FAO/PESA Centroamérica.

FAO (2005) Directrices voluntarias en apoyo de la realización progresiva del derecho a una alimentación adecuada en el contexto de la seguridad alimentaria nacional. Roma, FAO.

FAO (varios años) El estado de la inseguridad alimentaria en el mundo. Roma, FAO.

InStituto de Estudios del Hambre (2010) Hacia una nueva gobernanza de la seguridad alimentaria. Madrid, PROSALUS.

Pérez de ARmiño, K. (1998) El futuro del hambre. Población, alimentación y pobreza en las primeras décadas del siglo XXI. Bilbao, Cuaderno de Trabajo 22, HEGOA.

SEN, A. (1981) Poverty and Famines. An Essay on Entitlement and Deprivation. Oxford, Oxford University Press. 
WINDFUHR, M. Y JONSÉN, J. (2005) Soberanía alimentaria. Hacia la democracia en sistemas alimentarios locales. FIAN Internacional/ITDG Publishing.

WINDFUHR, M. Y JONSÉN, J. (2002) El derecho a no tener hambre. Bogotá, Universidad del Externado.

\section{Documentos citados}

Analysis of the word food crisis by the U.N special rapporteur on the right to food, Olivier de Schutter (2008). www.srfood.org/images/stories/pdf/otherdocuments/1srrtfnoteglobalfoodcrisis-2-5-08.pdf

Declaración de Córdoba sobre el derecho a la alimentación y la gobernanza del sistema mundial de agricultura y alimentación (2008). http://www.uco.es/ catedrasyaulas/cehap/memoriaactividades.html\#2008

Declaración de Nyéléni (2007). www.nyeleni2007.org/spip.php?article291

Declaración de Roma y Plan de acción de la Cumbre Mundial sobre la Alimentación (1996). www.fao.org/wfs/index_es.htm

Declaración universal sobre la erradicación del hambre y la malnutrición (1974). http://www.unhchr.ch/spanish/html/menu3/b/69 sp.htm

El derecho a la alimentación. Informe preparado por el Sr. Jean Ziegler, Relator Especial sobre el derecho a la alimentación, de conformidad con la resolución 2000/10 de la Comisión de Derechos Humanos (2001). E/CN.4/2001/53. http://daccessdds.un.org/doc/UNDOC/GEN/G07/103/46/PDF/G0710346. pdf? OpenElement

El derecho a la alimentación. Resolución de la Comisión de Derechos Humanos 2000/10 (2000). http://www.unhchr.ch/huridocda/huridoca.nsf/(Symbol)/E. CN.4.RES.2000.10.Sp? Opendocument

El mundo ya no necesita más de esta medicina (2008). www.escr-net.org/news/ news show.htm?doc id=688977\&attribLang id $=13441$

Informe del Relator Especial sobre el derecho a la alimentación, Jean Ziegler, presentado de conformidad con la resolución 2003/25 de la Comisión de Derechos 
Humanos(2004). E/CN.4/2004/10. http://www.unhchr.ch/Huridocda/Huridoca. nsf/O/a29580b15ae54551c1256e6300517e70/\%24FILE/G0410780.doc

La relación entre el Disfrute de los Derechos Humanos, en particular los derechos económicos, sociales y culturales, y la distribución de los ingresos. Informe final preparado porel Sr. JoséBengoa, Relator Especial(1997). E/CN.4/Sub.2/1997/9. http://daccessdds.un.org/doc/UNDOC/GEN/G97/129/57/PDF/G9712957. pdf? OpenElement

Los Derechos Económicos, Sociales y Culturales. El derecho a la alimentación. Informe del relator Especial sobre el derecho a la alimentación, Jean Ziegler (2005). E/CN.4/2005/47, Enero. hitp://daccessdds.un.org/doc/UNDOC/GEN/ G05/107/13/PDF/G0510713.pdf?OpenElement

Observación general n. ${ }^{\circ}$ 12: El derecho a una alimentación adecuada (1999). E/C.12/1999/5. http://www.unhcr.org/cgi-bin/texis/vtx/refworld/rwmain/ opendocpdf.pdf? reldoc $=y \&$ docid $=47 \mathrm{ebcce} 12$

Statement of the Special Rapporteur on the Right to Food Mr. Olivier De Schutter (2008). www.srfood.org/images/stories/pdf/otherdocuments/2-statementsrahhrc7final 1-22-5-08.pdf 